\title{
An epilogue Return to Kiriwina - the ethnographic film-maker as author
}

$\mathrm{I}_{\mathrm{e}}^{\mathrm{r}}$ there is a single general conclusion to be drawn from the multitude of examples of ethnographic film-making considered in the course of this book, it is that if one's purpose is to make an ethnographic film that goes beyond the merely descriptive, one should not attempt to eliminate, sidestep, or hide the authorship of that film, nor seek to consign it to others, be it the subjects of the film or the audience. Rather the aim should be to develop modes of film authorship that, while playing to the strengths of film as a medium of communication, also reflect contemporary ideas about the practice of ethnography more generally.

As I have described in this book, for around seventy-five of the $\mathrm{I} 2 \mathrm{O}$ or so years during which the moving image camera has been used for ethnographic purposes, its principal value was perceived, certainly in Englishspeaking academic anthropology, as being related to its capacity to copy the world in a mimetic manner. As such, it was seen as a device for collecting data in an objective fashion that could act as a control on the inevitably more subjective observations made through the human eye alone. Although this view of the moving image camera still surfaces from time to time, it has, by and large, been abandoned. Instead, it has come to be widely valued for its capacity - particularly when used in conjunction with a skilfully recorded soundtrack - to generate accounts of the world that are imbued with a strong sense of 'lived experience'.

In the General Introduction to this book, I suggested that in this capacity to evoke a sense of lived experience, ethnographic film-making offers the possibility of reconnecting with an aspect of human life that Bronislaw Malinowski, the original Ethnographer, sought to describe through his concept of the 'subjective desire of feeling', and which he detected in numerous practices and sentiments of everyday life among the people of 
the Trobriand Islands. Malinowski considered these 'imponderabilia' to be the 'flesh and blood' of social life and argued that their elicitation was even more important than the description of 'institutions, customs or codes', by which he meant social organisation and culture as systems of abstract ideas. Indeed, he went so far as to suggest that an ethnographic account that failed to include the 'subjective desire of feeling' would 'miss the greatest reward' to be obtained from the study of humankind.

However, notwithstanding this ancestral endorsement, in the last analysis the mere evocation of lived experience through film, however technically sophisticated, however sensorial, is never going to be sufficient to achieve an account of social life that is ethnographic in more than a superficial manner. In the first place, the experience evoked is never going to be very profound: it will always be highly vicarious, only a pale shadow of the experience of the subjects' life as they experience it, and even as experienced by the film-maker in the course of filming. Moreover, it pertains to only two of the five senses, sight and hearing (though if we allow for 'haptic' effects, we might include an element of touch as well). It is a form of experience in which the viewer is unable to make any intervention, nor suffer any consequence. If the evocation of lived experience through film is based on an informed awareness derived from the prolonged immersion of the film-maker in the world of the subjects, then it may certainly possess a certain ethnographic value in a purely descriptive sense. But the understanding that it can offer of that world is only ever going to be limited.

If one wants to go further and offer some insight as to why life is experienced in this way in this particular social situation, then it is necessary to anchor this evocation of experience in some social or cultural context. Or, to continue with Malinowski's corporeal metaphors, one should seek to relate the 'flesh and blood' practices of lived experience to what he called the 'skeleton' of a social group, that is, to its network of social relations, or to its 'spirit', its culturally specific ideas. In ethnographic film-making, the making of these connections often entails recurring to some form of language, be it the metaphorical language of cinematic narrative, or more literal forms of language in the form of verbal discourse by the subjects or by the film-maker themselves. The challenge of ethnographic film-making then is to find a way of authoring films that employ these forms of language without at the same time undermining the unique capacity of the medium of film to impart a sense of lived experience.

It is now just over a century since Malinowski found himself suddenly set down on a beach on Kiriwina, the largest of the Trobriand Islands, as the dinghy that had brought him there sailed away over the horizon. Although the fieldwork method that he developed there over the ensuing years, more by force of circumstance than by design, has since been much criticised, refined and diversified, the central principle on which it was based, namely, 
the first-hand immersion of the researcher in the life of the community of study over a prolonged period - only later dubbed 'participant-observation' - remains central to the ethnographic method. In a small homage to this anniversary then, let us end the narrative of this book in the most classical of fashions by returning to the beginning of the story - both of this book and of modern anthropology - and taking up Malinowski's famous invitation to imagine ourselves set down on that beach, but with the difference that among the gear with which we are surrounded is a modern digital filmmaking kit.

Let us imagine too that we have given ourselves the task of using that equipment to make a film about what Malinowski once described as 'perhaps the most difficult and bewildering aspect of Trobriand culture for the investigating sociologist', that is, the Trobriand funeral. ${ }^{1}$ There were many things about this event that attracted Malinowski's attention, but one feature that particularly intrigued him was that the extravagance of expressions of grief depended not on personal sentiment but rather on the precise nature of the kinship relationship between the mourner and the deceased. Moreover, the impact of these kinship relations on the practice of mourning was not what one might expect at a funeral in Europe, where it would be reasonable to posit that the closer the relative to the deceased, be it through blood or marriage, the more likely it would be that they would be openly grieving.

On Kiriwina, Malinowski discovered, things were not quite so straightforward. For when an eminent man died, his wife and children, along with all his relatives through marriage, would mourn ostentatiously, putting on rags for clothes, shaving their heads and 'howling like demons in despair'. In sharp contrast, the man's closest siblings would continue to dress normally, would not shave their hair, and although they might discretely weep, they would not 'parade' their grief.

Part of the reason for this difference, Malinowski claimed, was that in Trobriand society, which was intensely matrilineal, not only a man's wife and his relatives by marriage, but even his own children were regarded as 'mere strangers'. (So extreme was their matrilineal ideology that, as Malinowski famously reported elsewhere, the Trobrianders denied that a father played any role in the physiological reproduction of his children). But, if they really were 'mere strangers', why would they be grieving more openly than the man's closest siblings? This is where Trobriand ideas about sorcery come into play in Malinowski's account: for in a society that attributed most deaths to the work of sorcerers coming from outside, a man's wife and children, being 'mere strangers', would be among the prime suspects for having caused his death. Therefore, whatever their personal sentiments, it was imperative for them to express their grief in a dramatic, overt manner in order to deflect any suspicions of this kind. 
How would one go about making a film about the Trobriand funeral that took this cultural context into account? With the aid of modern film-making technology, we could set about evoking a strong experiential sense of what it would be like to be at a Trobriand funeral. With the long takes allowed by modern cameras and the sophisticated soundscapes made possible by digital audio technology, we could impart a subtly textured sense of both the physical space and of its acoustics. Through sensitive editing, we could communicate a sense of the duration of the funeral, its longueurs and its intensities, its experiential highs and lows. We could take care not to make this editing too slick, including some incidental, even discordant reality effects that would impart a sense of the ambiguity and flux of social life. By careful attention to narrative devices, we could engage the audience in the progression of the funeral to such a degree that they would have a sense of becoming entirely enfolded within the event themselves.

And yet, however effectively we might have evoked an embodied sense of the funeral in our film, if there were no reference to local ideas about matriliny and sorcery, the reasons why some people were 'howling like demons' and others were remaining stoically reserved would remain obscure. We might have been successful in communicating an experiential sense of the funeral, but it would have been entirely an outsider's sense of this experience, unmarked by the valency that the experience would have had for an insider. But if we wanted to provide the audience with sufficient understanding of the social and cultural context to make the experience of the funeral comprehensible in insider's terms, our aim should be to do so without so burdening the film with verbal explanations that destroyed the sense of 'being there'. The best method for reconciling these seemingly contradictory demands, I suggest, is to make sure, as far as is possible, that the necessary connections between practices, relations and ideas are made without leaving the diegesis, that is, the world created by the film.

One possible strategy would be to lay an explanatory verbal commentary over the images, but that can be quickly dismissed as it would undoubtedly turn the film into a ponderous pedagogical lecture and deprive it entirely of any sensorial quality. Alternatively, we might conduct formal interviews with some of the leading participants and ask them to tell us why some people were grieving more than others. But this too could lead the film to become too heavily dominated by speech.

So, instead, we could decide merely to follow the whole process of the funeral in an observational fashion - before, during and not forgetting afterwards - in the expectation that this would throw up, in the normal ebb and flow of events, in the informal conversations between the participants and in connection with the minor incidents surrounding the funeral, sufficient contextualising detail for the audience to understand why some people 
grieved more energetically than others. By adopting a participatory praxis, we could bring our key interlocutors into the process of elucidation, conducting with them what were, in effect, interviews as the event unfurled, but presenting them as contingent conversations. Once back in the edit suite, while respecting the chronology of the main constituent events of the funeral, we could move all these incidental events and conversational commentaries around, juxtaposing them as necessary, in order to throw light on the differential expressions of grief.

But as even this might not be sufficient to achieve our goal, we might also need to assist the process further by some discreet textual intertitles, or even, in the last resort, by some restrained lines of voice-over narration. The more it seemed that this narration emerged from within the world represented in the film itself, the better it would suit our purposes. In the ideal case, it would be the voice of a subject, either recorded as the funeral was ongoing, or afterwards, in response to a screening of the film in an edit suite. Failing that, it could be our own voice, particularly if that had been heard in synch on location. By appearing to belong within the world of the film, these voices, although in fact extraneous to that world, would minimise the disruption of the sense of 'being there' at the funeral on Kiriwina.

What we certainly could not do, at least not while still claiming to make a film of any significant ethnographicness, would be simply to show the mourners 'howling' at length without any form of contextualisation, as if the meaning of their grief were somehow self-evident and that the longer and the more sensorially we invited the audience to experience them grieving, the more its significance would become clear.

Rather, in order to make our imaginary ethnographic film about the Trobriand funeral, we would need to draw on all the knowledge and mutual confidence that we had managed to build up with our Trobriand hosts in order to work out with them the most effective way of fashioning an account that, without leaving the diegesis of the film, clarified the multiple connections between what the subjects were doing and what they were thinking, between what they were thinking and what they were feeling, between what they were feeling and the nature of their relationships to other people. In this way, we would then be well-placed to make a complex and textured ethnographic film, one that would go beyond the mere evocation of experience, beyond mere description, beyond observation.

Note

1 As described in Malinowski (I932b), I26-39. 